\title{
The insidious presentation of the juvenile form of metachromatic leucodystrophy
}

\author{
NeIL GoRdon \\ M.D., F.R.C.P. \\ Royal Manchester Children's Hospital, Pendlebury, Manchester
}

\begin{abstract}
Summary
Certain progressive cerebral diseases can present with emotional and behavioural disorders. The juvenile form of metachromatic leucodystrophy is one of these. The histories of two children with this condition are given to demonstrate the insidious form of onset.
\end{abstract}

\section{Introduction}

There are a number of cerebral diseases in childhood which can present with disorders of behaviour, suggesting the possibility of a psychogenic cause. Minor epileptic status (Brett, 1966), whatever its cause, can impair consciousness with few if any epileptic features such as myoclonus. The child may not have suffered from absences or other forms of minor seizures before the onset of the continuous epileptic activity which appears primarily to involve the subcortical structures. This causes a deterioration of intellectual functions including speech, with ataxia and salivation as typical symptoms. The status does not usually last for long at a time but the child's confusion is sometimes thought to be of 'hysterical' origin. Minor status is often of unknown origin and recovery can be complete, but in some instances it is due to degenerative cerebral diseases such as the gangliosidoses or Batten's disease.

It has been stressed that a wide variety of conditions from cerebral tumours to familial ataxias can be initially diagnosed as psychiatric disorders (Rivinus, Jamison and Graham, 1975). However, there are certain neurological diseases in which this is particularly likely to happen. Subacute sclerosing panencephalitis can occur several years after an attack of measles in infancy. The intervening period may be free of symptoms, although minor disabilities can occur (Donner, 1973). The child is noted to be failing at school and to be behaving in an odd manner. Deterioration is not necessarily rapid and the onset of obvious myoclonus can be delayed. Diffuse sclerosis (Schilder's disease) can cause central deafness and central blindness, as well as a progressive dementia, and the initial symptoms, leading as they do to fall-off in school performance, may be interpreted as evidence of an emotional disorder.
The purpose of this paper is to emphasize that the juvenile form of metachromatic leucodystrophy is another degenerative disease which can start with problems of behaviour and learning before there is obvious evidence of an organic disease. The first complaints may originate in school when the teacher expresses concern over the child's failure in lessons, after initial progress which has been quite satisfactory.

\section{Case reports}

The following case reports illustrate this mode of onset.

\section{Case 1}

A 7-year-old boy had been in good health until about a year before admission to hospital. Past history and family history were negative. His teachers began to be concerned over his progress. $\mathrm{He}$ seemed to be an immature boy who lived in a world of his own, although psychometric testing 6 months after the start of the illness showed him to be of average intelligence. From then on he did not advance in any aspect of his school work, and in some he deteriorated. His concentration and memory became limited, he could not dress himself properly after the Physical Education classes, and if not supervised at lunch-time he scattered his food.

Then similar behaviour at home began to cause his parents considerable worry. Gradually the boy became more disorganised and lacking in awareness of his surroundings. On the Wechsler Intelligence Scale for Children he remained within the average range of intelligence, but in the Burt Reading Test he was a year retarded, and read slowly with only a small sight vocabulary. A change of school was tried but this made no difference.

When his co-ordination and balance were obviously worse he was referred for investigation. After 10 months of illness his gait was so unsteady that he had to be held by the hand and he often fell. He had ceased to play with toys and ate anything that was available. His speech was slow and he dribbled a lot. On examination, apart from the ataxia, the tendon reflexes were brisk and the plantar responses were 
extensor. Further deterioration occurred in hospital, incontinence of urine and faeces developed, speech became more difficult to understand, and spasticity of the limbs, especially on the left side, increased. There was dragging of the left foot on walking any distance. The intellect deteriorated quite rapidly and he was soon not even able to write his name and lost himself in familiar surroundings.

Tests included a normal urinary and serum aminoacid chromatogram. The CSF protein was slightly raised but the fluid was otherwise normal. There was no raised measles antibody titre in serum or CSF. The EEG showed only a slight increase of generalized slow wave activity. On axial computerized tomography (EMI Scan) there was some dilatation of the left lateral ventricle but no other abnormal features. Motor nerve conduction rates were reduced, especially for the right lateral popliteal nerve (latency at knee $14.0 \mathrm{~m} / \mathrm{sec}$, latency at ankle $6.8 \mathrm{~m} / \mathrm{sec}$, distance knee to ankle $19 \mathrm{~cm}$, conduction velocity $26 \mathrm{~m} / \mathrm{sec}$ ). The features were consistent with a peripheral neuropathy of a demyelinating type. White cell enzyme assay showed a deficiency of arylsulphatase A activity, $0.74 \mu \mathrm{mol} / \mathrm{g} / \mathrm{hr}$, (normal range 60-260 $\mu \mathrm{mol} / \mathrm{g} / \mathrm{hr}$ ). The mother's level was $33 \mu \mathrm{mol} / \mathrm{g} / \mathrm{hr}$ and the father's $41 \mu \mathrm{mol} / \mathrm{g} / \mathrm{hr}$, values compatible with heterozygous carriers. Examination of a 24-hr collection of urine confirmed a grossly abnormal sulphatide excretion on thin layer chromatography of extracted urine sediment.

\section{Case 2}

A 6-year-old girl was referred to hospital by her headmistress because of increasing unsteadiness and clumsiness at school. Her mother's pregnancy had been normal and the birth weight was $3.29 \mathrm{~kg}$ but there had been some difficulty in establishing respiration after birth. Her progress had been satisfactory up to about 6 months before admission to hospital. Then the child's school teachers noted that her work began to slow down and she often seemed to be 'day-dreaming'. She showed some nervousness when reading and it was thought at school that her mother might be putting pressure on her at home. She started to fall increasingly often, sometimes not putting out her hands to save herself, and she had difficulty in getting up stairs. Eating became messy and there was confusion with dressing. Her writing was noted to be slow and untidy, and her reading ability lessened.

The deterioration in her condition slowly continued over the next 2 months and she started. to suffer from urinary incontinence. Her speech was affected as she seemed to have to force words out, as if she knew what she wanted to say but could not articulate them. Six months after the onset of the illness there was a tremor of the arms, worse on action, and the gait was stiff and awkward. The tendon jerks were very brisk and the plantar responses were extensor.

The child had never had any other illness of note and the family history was negative.

Examination on admission to hospital confirmed the abnormal neurological findings, with a mixture of ataxia and spasticity. Her speech was slow and slightly confused but she was co-operative in carrying out tests, although there was considerable difficulty in even writing her name. On investigation there was a normal urine amino-acid chromatogram, and an EEG with an excess of slow wave activity especially on the left side. The motor nerve conduction velocities distally were reduced (right lateral popliteal nerve knee-ankle, $29 \mathrm{~m} / \mathrm{sec}$; right ulnar nerve wristelbow $32 \mathrm{~m} / \mathrm{sec}$ ), findings compatible with a segmental demyelinating lesion. Leucocyte enzyme studies showed a marked deficiency of arylsulphatase A with a level of 3.1 $\mu \mathrm{mol} / \mathrm{g} / \mathrm{hr}$ (normal range 60-260 $\mu \mathrm{mol} / \mathrm{g} / \mathrm{hr}$ ). Chromatography of extracted urine sediment confirmed abnormal amounts of sulphatides compatible with the diagnosis of metachromatic leucodystrophy. The father's and mother's arylsulphatase A levels were $78 \mu \mathrm{mol} / \mathrm{g} / \mathrm{hr}$ and 58 $\mu \mathrm{mol} / \mathrm{g} / \mathrm{hr}$. Their arylsulphatase B levels were 85 $\mu \mathrm{mol} / \mathrm{g} / \mathrm{hr}$ and $59 \mu \mathrm{mol} / \mathrm{g} / \mathrm{hr}$ (normal range $20-80$ $\mu \mathrm{mol} / \mathrm{g} / \mathrm{hr}$ ), the $\mathrm{A} / \mathrm{B}$ ratios being 0.92 and 0.98 (normal range $2 \cdot 0-7 \cdot 0$ ) so that even though the arylsulphatase $\mathbf{A}$ activity is at the lower limit of the normal range the $\mathrm{A} / \mathrm{B}$ ratio is low and the findings cannot exclude a heterozygous state.

\section{Discussion}

The onset of juvenile metachromatic leucodystrophy is usually between the ages of 5 and 10 years. It often starts with failure of school work and emotional lability, and there can be slight visual disturbances (Austin, 1965). In the two children described in this paper the duration of symptoms before the onset of definite organic features was 6-7 months and 5-6 months respectively, emphasizing the insidious development of this disease. Metachromatic material can be found in the peripheral nerves and urine (Menkes, 1966) but obviously the diagnosis has to be confirmed by leucocyte enzyme studies and the demonstration of abnormal sulphatide excretion in the urine.

As vitamin $A$ is essential to the metabolism of sulphatides a vitamin A deficiency diet has been tried. No improvement was noted in the case of one child (Melchoir and Clausen, 1968), but in another there appeared to be an arrest of the condition over a 2-year period (Moosa and Dubowitz, 1971). Beefbrain arylsulphatase A given intravenously did not improve the condition, but infusion of separated leucocytes can increase the enzyme activity for a few 
weeks (Raine, 1975). It is to be hoped that more effective methods of enzyme replacement can be developed in the future, and the diagnosis of an organic disease must not lessen the importance of the management of the emotional reactions of the child and the family (Rivinus et al., 1975).

\section{Acknowledgments}

I wish to thank the staff of the Willinck Laboratory, Royal Manchester Children's Hospital, for the results of the biochemical investigations.

\section{References}

AUSTIN, J.H. (1965) Mental retardation-metachromatic leucodystrophy. In: Medical Aspects of Mental Retardation (Ed. by Carter, C.H.). Charles C. Thomas, Springfield, Illinois.

BreTt, E.M. (1966) Minor epileptic status. Journal of Neurological Science, 3, 52.
DoNNER, M. (1973) Clinical aspects of a slow virus encephalopathy: subacute sclerosing panencephalitis. European Study Group on Child Neurology, Kungalv, Sweden.

Melchior, J.C. \& Clausen, J. (1968) Metachromatic leucodystrophy in early childhood: treatment with a diet deficient in vitamin A. Acta paediatrica scandinavica, 57, 2.

Menkes, J.H. (1966) Chemical studies of two cerebral biopsies in juvenile metachromatic leukodystrophy: the molecular composition of cerebrosides and sulphatides. Journal of Pediatrics, 69, 422.

MoosA, A. \& Dubowitz, V. (1971) Late infantile metachromatic leucodystrophy. Archives of Disease in Childhood, 46, 381 .

RAINe, D.N. (1975) The Treatment of Inherited Metabolic Disease. Medical and Technical Publishing Co. Ltd, Lancaster.

Rivinus, T.M., Jamison, D.L. \& Graham, P.J. (1975) Childhood organic neurological disease presenting as psychiatric disorder. Archives of Disease in Childhood, 50, 115. 